Acta Agroph., 2019, 26(2), 61-76

doi: $10.31545 /$ aagr/111886

\title{
TOTAL ANTIOXIDANT CAPACITY AS AN IMPORTANT ELEMENT IN THE ASSESSMENT OF SOIL PROPERTIES FOR THE PRODUCTION OF HIGH-QUALITY AGRICULTURAL AND HORTICULTURAL RAW MATERIALS WITH HEALTH-PROMOTING PROPERTIES
}

\author{
Barbara Skwaryto-Bednarz $\mathbb{0}$ \\ Department of Plant Protection, University of Life Sciences, Akademicka 13, 20-950 Lublin, Poland \\ e-mail: barbara.skwarylo@up.lublin.pl
}

\begin{abstract}
Soil is one of the most important elements of the natural environment, it is characterized by the highest resistance to degradation. It is the first element in the trophic chain and may have different effects on the health condition of people, primarily through the consumption of plant raw materials. One of the effects of soil contamination is the formation of excess free radicals in cells, which leads to oxidative stress. Free radicals contribute to the damage of lipids, proteins, mitochondrial and nuclear DNA and also to disorders in the signalling pathways responsible for the broad spectrum of cellular responses. The result of this is the emergence of many diseases, such as cancer, cardiovascular disorders, osteoporosis, inflammation, Alzheimer's disease, Parkinson's disease. However, it is possible for people to protect themselves from the excess of free radicals found in soils and cultivate plants in the best quality soils. The best way to assess soil quality is to determine its total antioxidant capacity using the different methods available (FRAP method, CUPRAC method, FOLIN-CIOCALTE method, $\mathrm{ABTS}^{+}$method, $\mathrm{DPPH}^{+}$method). Such designations make it possible to assess the soil in terms of its suitability for the production of high-quality food or the possible need for reclamation. It should be noted that soil quality may be improved by adding antioxidant compounds to it, which in turn will increase the amount of antioxidants in agricultural raw materials. One of the ways to achieve this is balanced fertilization, especially organic, but also mineral.
\end{abstract}

Keywords: antioxidant capacity, soils, antioxidants, human health

\section{INTRODUCTION}

There is an increasing awareness of the fact that ill-considered human activity, primarily through the pollution of elements of the natural environment, i.e. water, air and soil, has transformed it into the anthroposphere (Frątczak 1996). For many years there have been significant positive changes, inspiring optimism that we are not only attempting to restore homeostasis in our environment, but also taking 
care to ensure its quality (Kopeć 2008, Sander 2008). This is unquestionably a favourable course of action, as pollution of the natural environment results in the generation of aggressive free radicals, which attack healthy cells and thus affect human health. An uncontrolled increase in their concentrations is referred to as oxidative stress (Krzeszowiak 2013). Its primary effects in cells are damage to DNA, carbohydrates and proteins, and lipid peroxidation. This may lead to a number of diseases, including neurodegenerative diseases such as Alzheimer's or Parkinson's disease and lateral amyotrophic sclerosis (Jodko-Piórecka and Litwinenko 2010), as well as cancer, cardiovascular disease, osteoporosis, inflammatory diseases, or lipofuscinosis. Scientific research has confirmed that effective defence against free radicals is possible. The human body has developed defence mechanisms known as antioxidant mechanisms, which are controlled not only by antioxidant enzymes, but also by antioxidants. These ensure that an oxidative/anti-oxidative balance is preserved in the cell (Krzepiłko 2005). Antioxidants can be supplied to the human body either naturally or pharmacologically. One solution is to ingest them with foods derived from the soil. They should be acquired from high quality soils, which have favourable physicochemical and also biological properties. This can be achieved with the use of appropriate horticultural procedures and organic and mineral fertilizers. The properties of soils contribute to the accumulation of numerous potential antioxidant compounds. These are taken up by plants and then ingested by people, which influences their health.

This study focuses on the impact of threats to the soil environment on human health and discusses the most important ones. It presents the role of monitoring in the protection of the soil environment and human health, and what it must include to be complete and to reflect the physicochemical and biological status of the soil. Antioxidants are characterized and emphasis is placed on how their quantities in the soil environment, raw materials, and products of plant origin affect human health. Selected methods for their determination in soil, i.e. the total antioxidant capacity of soils, are presented.

\section{The effect of the natural environment on human health}

Humans exist in the natural environment and are directly connected to it through the air and water, and indirectly through the soil (Dobrzański et al. 1997, Korzeniowski 2012). During their evolution, humans adapted to the natural variability of the chemical and physical parameters of their environment (Dobrzański et al. 1997), but excessive anthropogenic changes in the immediate environment have begun to surpass their ability to adapt. The homeostasis between the elements and compounds of the body, which should be in a state of dynamic equilibrium with the immediate surroundings, has been disturbed. Both a deficiency and an excess of these substances poses a danger to human health (Kośla 1999). This is particularly important in the case of trace elements. 
Health in relation to the natural environment is defined as a certain psychophysical state of an individual conditioned by the structure of the organism and results from a dynamic balance between the organism and the environment (Wolański 1990). Any disruption of this balance leads to a disease process, mainly by impairing the immune process. This ultimately results in damage to defence mechanisms and thus susceptibility to disease.

\section{Contamination of the soil environment and human health}

Soil is not only an important element of the natural environment, but also the first and fundamental link in the food chain: soil $\rightarrow$ plant $\rightarrow$ animal $\rightarrow$ human (Górski 2006, Rosada and Przewocka 2017). It affects human health in varying degrees, mainly through the consumption of plant raw materials (Mrozowska 1999). Several thousand years ago Hippocrates said, 'All diseases come to man through the mouth with food.' It is now well known that food may contain mutagenic or carcinogenic compounds, but also substances that can prevent these processes and phenomena, i.e. antioxidants.

The soil environment can affect human health not only through the consumption of food, mainly of plant origin, but also via the inhalation of soil particles (Mrozowska 1999). However, this phenomenon only occurs in certain places and is associated primarily with wind erosion of soil in various parts of the world. Human health may also be affected by various pathogenic microbes, which enter the human body mainly through damaged skin.

Chemical pollutants (particulates and gases) are among the most hazardous pollutants in the soil environment. They enter plants and then the human body through food originating in the soil. Chemical contaminants, which are most often introduced into the soil for economic purposes, have a detrimental effect on human health. The most dangerous of these are heavy metals, pesticides and nitrosamines.

\section{Monitoring of land and soil quality}

Monitoring the quality of land and soil is important not only as an element of protection for the natural environment, but also for human health. It is included as a fundamental element of State Environmental Monitoring in Poland (Stepnowski et al. 2010). Monitoring the soil environment is a complex system and is conducted by the Institute of Soil Science and Plant Cultivation (IUNG) in Puławy, at measurement and control points throughout the country (Stepnowski et al. 2010). Monitoring the current state of the soil and land is carried out in four stages. Stage 1 (the preliminary stage) involves indicating areas most likely to be polluted, drawing up a list of hazardous substances posing a threat, and recording this information in a register of contaminated sites. 
Stage 2 involves confirming or in some cases ruling out the presence of the previously identified chemical compounds by performing preliminary measurements. Measuring points for preliminary tests are chosen and their geographical coordinates are determined by GPS (Global Positioning System), to the nearest metre. The substances detected and identified are subjected to detailed analysis and their concentrations are determined (Stage 3). The fourth and final stage consists of the preparation of complete documentation concerning the exceedances of soil and land quality standards (registry of areas) and the indication of land for reclamation (Stepnowski et al. 2010).

The most important goals of soil monitoring may be summarized as follows (Bednarek et al. 2005):

- assessment of the direction and rate of soil changes under the influence of external factors;

- determination of the tolerance limits of various natural environments to external factors;

- anticipation of and early information about imminent changes;

- development of recommendations and preventive measures in the case of anticipated adverse changes.

Soil monitoring in Poland and around the world usually consists of the determination of the following parameters (Bednarek et al. 2005):

- trends in and the rate of change in land use;

- progression of water and aeolian erosion;

- changes in soil structure;

- changes in the rate of accumulation or loss of humus and changes in its quality;

- balance of macroelement resources;

- changes in water and heat conditions in irrigated or drained soils;

- dynamics of soil contamination by industrial emissions and other pollutants;

- dynamics of soil contamination by radioactive substances;

- changes in soil reaction.

Less frequently determined parameters included in soil monitoring are changes in redox potential, changes in the composition and activity of soil microflora and fauna, and quantitative and qualitative changes in the metabolic products of these organisms, this is known as biomonitoring (Mrozowska 1999).

In biomonitoring, the frequency of observations is adjusted to the rate of the processes being monitored. One difficulty is that changes in soil properties and functions usually occur some time after the factors that induce them (Mrozowska 1999). The essence of soil monitoring is to track the changes occurring in soils in the adopted time intervals, which can range from several days or weeks or even to decades. It is important for soil samples used in repeated, periodic laboratory tests to be taken from the same sites as the previous samples (Mrozowska 1999). 
Based on toxicological tests, a risk assessment is performed for a given population in terms of mortality, growth, reproduction, and disorders of other physiological processes (Mrozowska 1999).

It follows from the above that full soil monitoring in environmental protection should include the testing of the physiochemical properties of soil as well as biological tests, including the numbers of soil microorganisms and their physiological groups and the determination of enzyme activity. This will provide information concerning the fertility of soils (Myśków et al. 1996). If the monitoring process is to be conducted to protect not only the environment, but human health as well, it should be expanded to include testing of the total antioxidant capacity of soils, which may reflect the intensity of the redox processes in the soil.

\section{Reactive oxygen species}

Reactive oxygen species (ROS) mainly include oxygen compounds and nitrogen compounds (Bartosz 2003, Karbarz 2010, Krzepiłko 2005, Gajewska et al. 2005) (Table 1).

Table 1. Selected examples of reactive oxygen and nitrogen species (Bartosz 2003, Karbarz 2010)

\begin{tabular}{lc}
\hline \multicolumn{1}{c}{ Name } & Formula \\
\hline Hydroperoxyl radical & $\mathrm{HO}_{2}{ }^{\circ}$ \\
Superoxide radical & $\mathrm{O}_{2}{ }^{-}$ \\
Singlet oxygen & $\mathrm{O}_{2}$ \\
Ozone & $\mathrm{O}_{3}$ \\
Hydrogen peroxide & $\mathrm{H}_{2} \mathrm{O}_{2}$ \\
Hydroxyl radical & $\mathrm{OH}^{\circ}$ \\
Nitric oxide & $\mathrm{NO}^{\circ}$ \\
Nitric dioxide & $\mathrm{NO}_{2}{ }^{\cdot}$ \\
Alkoxyl radical & $\mathrm{RO}^{\bullet}$ \\
Peroxyl radical & $\mathrm{ROO}^{\circ}$ \\
\hline
\end{tabular}

ROS are extremely reactive and toxic to cells. They damage them through nonspecific reactions with their components, i.e. sugars, proteins, lipids, nucleic acids (DNA and RNA) and virtually all biomolecules found in the cell. ROS arise as a result of the physiological and metabolic processes taking place in cells, and their concentrations are controlled by both antioxidant enzymes and antioxidants. Scientific research shows that the concentration of free radicals in cells may increase under the influence of various environmental factors, i.e. chemical pollution, including soil contamination, as well as physical factors, such as ionizing and ultraviolet radiation, ultrasound, air pollution, tobacco smoking and fires. This ultimately leads to oxidative stress (Sies 1995). Research shows that the induction 
of pro-oxidative processes and the impairment of antioxidant mechanisms are most likely due to imbalances of elements in the body, which are associated with excessive exposure to some metals (especially heavy metals) (Bombolewska et al. 2013).

\section{Antioxidants}

Antioxidants are substances that occur most often in low concentrations when compared to oxidizable compounds and which delay or inhibit their oxidation. These compounds inhibit oxidation reactions by reacting with oxidizing agents (preventive antioxidants) or with oxidation intermediates, such as free radicals (chain-breaking antioxidants) (Halliwell and Gutteridge 1995, Karbarz 2010). The preservation of the pro-oxidative/anti-oxidative balance in the cell requires the interaction of the antioxidant enzyme system and antioxidant molecules. Scientific research shows that the first line of defence against the adverse effects of free radicals is always superoxide dismutase, catalase and glutathione reductase (Bartosz 2003). Compounds that perform antioxidant functions in cells, inhibiting free radical reactions in the early stages of their propagation, include numerous compounds with varied chemical structures. These include macromolecular antioxidants: enzymes - catalase (CAT), glutathione reductase (GRd), glutathione peroxidase (GPx), and superoxide dismutase (SOD) (Karpińska and Gromadzka 2013); amino acids - cysteine and glutamic acid; hormones - DHEA and melatonin; coenzyme $\mathrm{Q}_{10}$; and the endogenous tripeptide glutathione (g-Glu-Cys-Gly), which occurs in the cytoplasm, mitochondria and cell nucleus (Wiktorowska-Owczarek and Nowak 2010). The natural antioxidants (low-molecular-weight antioxidants of natural origin) most often supplied to the human body are vitamin C (tomatoes, red pepper, cruciferous vegetables, onion, garlic, red beets), cryptoxanthin (red pepper), lycopene (tomatoes), polyphenols (cruciferous vegetables and buckwheat - phenolic acids and catechins; potatoes and coffee - chlorogenic acid; tea and cocoa - catechins; soy - isoflavones; red beans and blueberries - anthocyanins; onion - quercetin), vitamin E, and vitamin A (Combs 2001, Sroka et al. 2005).

\section{Antioxidants in the soil environment}

Soil is an extremely dynamic system (Mrozowska 1999). Numerous chemical reactions are constantly taking place in it. Some of the most common ones are redox reactions (Baran 2000). The simplest example of these is the biodegradation of organic matter, which involves free radicals. Redox processes in the soil take place with varying intensity.

Literature reports confirm that the most antioxidant substances in the soil are found among the humic compounds contained in humus. Schepetkin et al. (2002) and Rimmer (2006a) emphasize that humic acids contained in humus have strong antioxidant 
properties in the soil. The high content of antioxidant humic substances in the soil may influence the chemical processes taking place in the rhizosphere, especially the transport of water and nutrients, redox reactions, secretion of organic acids, sugars, phenols and amino acids by plant roots, and chelate formation (Baran et al. 1999).

The level of antioxidants in soil and plants is affected by heavy metals. Sharma and Agrawal (2005) report that excessive amounts of heavy metals transferred to plants from the soil adversely affect the level of antioxidants in plant products, and through consumption of these plants have a detrimental effect on human health. This finding was confirmed by other researchers (Zhi-Ting Xiong and Hai Wang 2005).

During the decomposition of soil organic matter, phenolic compounds known for their antioxidant properties are generated. Phenolic compounds present in the soil environment include a broad spectrum of chemical compounds, such as phenol or chlorophenols. The chemical compounds in humus known for their antioxidant properties include phenolic acids (derivatives of benzoic and cinnamic acid), flavonoids (flavones, flavanols, flavonols, isoflavones and anthocyanins) and metabolic products of soil microorganisms.

All antioxidant chemical compounds in the soil counteract the negative effects of reactive oxygen species and control their concentration. ROS are generated, for example, during the biodegradation of lignins in the soil (Rimmer 2006). This process involves enzymes produced by certain fungal species (Hammel et al. 2002). They secrete peroxidase and hydrogen peroxide, a reactive oxygen species, into the environment. Other radicals such as the hydroxyl radical are involved in the depolymerization of polyphenolic compounds. Humus itself also contains numerous free radicals (Rimmer 2006b). Their concentration in the soil may increase under the influence of various chemical contaminants present in the soil.

\section{Total antioxidant activity of soils and selected methods used to determine it}

The total antioxidant capacity (TAC) of soils is a measure of their ability to prevent unfavourable processes and oxidation reactions through compounds contained in the soil that can enter into redox reactions. Hence, the total antioxidant capacity of soils can be measured to determine the intensity of redox processes in the soil environment. According to Rimmer (2006a), this parameter makes it possible to compare the total antioxidant capacity not only of different soils, but of their soil horizon levels as well. This allows for the estimation of the degree of degradation of the soil, including soil organic matter.

Currently, all of the methods described for the determination of the antioxidant capacity require the test substance to be in a dissolved form ( $\operatorname{Re}$ et al. 1999). Therefore, to study the antioxidant properties of soil, a soil extract must be prepared. Many authors emphasize that in the case of soils a procedure must be developed for the extraction of all antioxidant substances, not only those that are easily soluble 
in water (Rimmer 2006a, b). Insoluble antioxidants may also be present in the soil, especially in resistant organic matter (Rimmer 2006a). This is a very difficult analysis to perform accurately as it should be remembered that the choice of extraction method significantly influences the quality of the determination. The extraction may be carried out with distilled water, ethyl alcohol or acetone.

Two categories of methods are used to determine total antioxidant capacity (TAC), also referred to as antioxidant activity (AA) (Wilczyńska 2009):

1. reduction of metal ions to ions with a lower oxidation state using a tested antioxidant (FRAP, CUPRAC);

2. scavenging of free, stable radicals (ABTS or DPPH) (Barto et al. 2005, Cybul and Nowak 2008).

\section{FRAP method}

Testing the total oxidative capacity of a solution using the FRAP method (Ferric Reducing Antioxidant Power) is aimed at determining its ability to reduce $\mathrm{Fe}^{3+}$ ions to $\mathrm{Fe}^{2+}$ ions, which are complexed by the compound TPTZ (2,4,6-tris(2-pyridyl)-1,3,5-triazine). An intense blue colour appears, with an absorbance maximum at $593 \mathrm{~nm}$ (Wilczyńska 2009). The total antioxidant capacity of a given sample is evaluated by comparing the change in absorbance $\Delta \mathrm{A}$ with the $\Delta \mathrm{A}$ value of the $\mathrm{Fe}^{2+}$ standard solution. The FRAP unit specifies the ability a solution to reduce 1 mole of $\mathrm{Fe}^{3+}$ to $\mathrm{Fe}^{2+}$. The FRAP method can be used to determine the total antioxidant capacity of body fluids, cells and tissues (Benzie and Strain 1996) or plant raw materials (Benzie and Strain 1999, Wilczyńska 2009). The $\Delta \mathrm{A}$ value of the sample is always directly proportional to the concentration of the antioxidant, and the change in absorbance $\triangle \mathrm{A}$ is converted into FRAP units by making a comparison with the standard solution according to the following formula (Wilczyńska 2009):

$\Delta \mathrm{A}_{593 \mathrm{~nm}}$ sample $/ \Delta \mathrm{A}_{593 \mathrm{~nm}}$ standard $\times$ FRAP value of the standard $(1000 \mu \mathrm{M})$

\section{CUPRAC method}

This is a variant of the FRAP method. To measure the antioxidant capacity of the sample, the CUPRAC (cupric reducing antioxidant capacity) method exploits the reduction of $\mathrm{Cu}^{2+}$ ions to $\mathrm{Cu}^{+}$ions, which are bound in a complex with bathocuproine (2,9-dimethyl-4,7-diphenyl-1,10-phenanthroline) or neocuproine (2,9-dimethyl-1,10-phenanthroline). The absorption maximum for the orange complex $\mathrm{Cu}(\mathrm{I})$-bathocuproine occurs at $490 \mathrm{~nm}$ and for the orange-yellow complex $\mathrm{Cu}(\mathrm{I})$-neocuproine at $450 \mathrm{~nm}$. The reaction takes place in a solution of ammonium acetate, i.e. in a neutral environment (Apak et al. 2008). The standard substance is usually Trolox or ascorbic acid. The reagent in the CUPRAC method reacts quickly 
enough to oxidize thiol antioxidants (Apak et al. 2005). The absorbance values of the individual components of the antioxidant mixture show additivity, and the resulting $\mathrm{Cu}^{+}$ions are bound in a stable complex and are not a potential oxidizing agent for hydrogen oxide (I). Due to all of these advantages, the CUPRAC method is often used to determine the reducing abilities of food samples (Yıldiz et al. 2008) and can be adapted to determine the total antioxidant capacity of soil solutions.

\section{Folin-Ciocalteu method}

This method consists of measuring the absorbance of the complex resulting from the reduction of salts of phosphotungstic and phosphomolybdic heteropoly acids, known as Folin-Ciocalteu reagent. It is prepared by mixing sodium tungstate $\left(\mathrm{Na}_{2} \mathrm{WO}_{4}\right)$, sodium molybdate $\left(\mathrm{Na}_{2} \mathrm{MoO}_{4}\right)$, lithium sulphate $\left(\mathrm{Li}_{2} \mathrm{SO}_{4}\right)$, bromine water and concentrated hydrochloric and phosphoric acid (Pękal 2014). During the reaction $\mathrm{Mo}^{6+}$ ions are reduced to $\mathrm{Mo}^{5+}$ ions, resulting in a blue colour. In an acidic environment this reaction is slow, and for this reason the measurement is most often performed at $\mathrm{pH} 10$ (Prior et al. 2005). In these conditions, phenols dissociate. This method may be modified to measure the reducing capacities of hydrophilic and lipophilic antioxidants at the same time (Georgé et al. 2005). $\mathrm{NaOH}$ is added to the environment for this purpose and the FC reagent is diluted with 2-methyl-1-propanol in a 1:2 volume ratio. Samples of model compounds, such as quercetin, Trolox, catechin, $\alpha$-tocopherol, ascorbic acid and glutathione, are prepared in acetone. The reaction is carried out for 20 minutes without light at room temperature (Pękal 2014). After about 50 minutes the absorbance is measured at $765 \mathrm{~nm}$. The method is used to determine the reducing capacity of natural samples - plant extracts, food, and drugs containing phenolic groups. The results are usually expressed as gallic acid content following the preparation of a calibration curve. The FolinCiocalteu method is often referred to in the literature as a method for determining the total amount of polyphenols in a sample.

\section{$\mathrm{ABTS}^{+}$method}

1. The determination of the total antioxidant capacity by the ABTS method according to Re et al. (1999), as modified by Bartosz (2003), uses sensitive responses between the $\mathrm{ABTS}^{+}$radical cation (2,2'-azino-bis(3-ethylbenzothiazoline-6-sulphonic acid) radical cation) and antioxidant substances. The antioxidant substances in the test solution (extract) react with $\mathrm{ABTS}^{-+}$radical cation, and the decrease in absorbance is proportional to the content of all antioxidants in the sample. The total antioxidant capacity of the test sample is expressed in Trolox (a synthetic vitamin E analogue) equivalents. The decrease in absorbance a short time after the solutions are mixed is a measure of the content of fast-acting antioxidants in the sample. In 
soil extracts, these may be phenolic compounds contained in humus or the metabolic products of soil microbes. The decrease in absorbance after 30 minutes is a measure of the content of all antioxidants in the sample.

2. The determination of TAC according to Rice-Evans and Miller (1991) involves adding 2,2'-azino-bis(3-ethylbenzothiazoline-6-sulphonic acid (ABTS) and hydrogen peroxide, peroxidase, or myoglobin, acting as a pseudoenzyme which catalyses the single-electrode oxidation of ABTS by hydrogen peroxide, in the presence of the test material. This results in the formation of the blue-green ABTS ${ }^{++}$ radical cation. The more antioxidants which are present in the soil extract, the more slowly the green colour will appear. After a specified incubation time, this colour is a measure of the content of antioxidants. The TAC results are expressed as Trolox equivalents (Bartosz 2003).

\section{DPPH $^{+}$method}

This method is used to determine the most reactive antioxidant components in a sample using a DPPH solution. The DPPH radical is purple in an alcohol solution, with a maximum absorbance value at $515 \mathrm{~nm}$ (Wilczyńska 2009). During the reaction, it captures the electrons from the antioxidant and turns into the weakly coloured product, causing the reaction mixture to turn yellow. This change is monitored by spectrophotometry. The measure of antioxidant activity is the parameter $\mathrm{IC}_{50}\left(\mathrm{EC}_{50}\right)$, which specifies the antioxidant concentration resulting in a $50 \%$ decrease in the initial concentration of the radical (Wilczyńska 2009). The content of antioxidants in the tested product can also be expressed as the equivalents of a reference substance (Randox, Trolox or ascorbic acid) per unit of mass or volume (Cybul and Nowak 2008, Wilczyńska 2009).

The results of the measurement are usually given as the amount of equivalents of the reference substance or as the degree of scavenging (fraction of loss of absorbance) of the radical, AA\% (Wilczyńska 2009):

$$
A A \%=\left[\left(A_{B}-A_{A}\right) / A_{B}\right] \times 100,
$$

where: $A_{A}-$ absorbance of the test sample; $A_{B}-$ absorbance of the control sample (Baltrusaiyte et al. 2007).

Research by Skwaryło-Bednarz and Krzepiłko (2007) has shown that soils, depending on the type, differ not only in their physicochemical and biological properties, but in their antioxidant properties as well. The authors analysed and compared the total antioxidant capacity (TAC) of brown rendzinas, brown soil and acidic podzolic soil using the ABTS method. This research determined that the greatest total antioxidant capacity occurred in brown rendzina. It was more than $30 \%$ 
higher than that of brown soil and about $65 \%$ higher than in acidic podzolic soil. In addition, it was observed that fresh soil samples had a higher TAC value than air-dried soil, which was probably linked to the activity of soil microorganisms.

The effect of the antioxidant content in soil on the quantity of antioxidants in food products

Foods of plant origin are a rich source of compounds with antioxidant properties. These include polyphenols (phenolic acids and a large group of flavonoids and anthocyanins), vitamins A and C, tocopherols, carotenoids, organic acids, calcium, selenium, chlorophyllins, glutathione, indoles, phytates, thiocyanates, and linoleic acid isomers (Szajdek and Borowska 2004). Research shows that substrates rich in humic compounds increase the quantity of antioxidants in plants (Aminifard et. al 2013, Jarosz 2006, Rimmer 2006a, Shiow and Hsin Shan 2003). From research by Aminifard et al. (2013) it follows that the antioxidant effect of the fruit and the quality of sweet pepper (Capsicum annuum L.) depends on the level of the compost dose $\left(0,5,10\right.$ and 15 tons $\left.\mathrm{ha}^{-1}\right)$. The highest antioxidant activity was obtained in plants with a dose of 10 tons ha ${ }^{-1}$ compost. The results obtained by Aminifard et al. (2013) prove that compost has a strong impact on fruit quality and on the antioxidant compounds of pepper plants under field conditions. For these reasons, the compost may be regarded as a preliminary bioprocessing stage to improve the antioxidant effect of the fruit and the quality of the pepper. However, a study by Jarosz (2006) showed that tomatoes of the Cunero F1 variety grown on peat accumulated significantly more vitamin $\mathrm{C}$, total sugars, total nitrogen and potassium than those produced on mineral wool or sand. Significant dependencies between the amount of antioxidants in food and their content in soil have been scientifically documented (Shiow and Hsin Shan 2003, Umińska 1990). The physicochemical properties of soil significantly determine the chemical composition of plants, this finding has been confirmed by research. Łata and Wińska-Krysiak (2006) have found that podzolic soil under specific conditions can stimulate the synthesis of ascorbate and low-molecular-weight thiol compounds, which is conducive to the accumulation of antioxidant compounds in kale. Numerous studies have demonstrated that humic compounds contained in humus can affect the biological activity of soil, including redox reactions, and influence the soil-plant interactions in the rhizosphere (Schepetkin et al. 2002, Rimmer 2006a, Skwaryło-Bednarz and Krzepiłko 2008).

Literature reports confirm the highly beneficial effect of increasing the amount of organic matter in the soil on crop quality and yield. A study by Verma et al. (2015) showed that the use of compost prepared using Effective Microorganisms and half of the recommended dose of chemical fertilizers (N50P30K25 + EM compost at the rate of $5 \mathrm{t} \mathrm{ha}^{-1}$ ) significantly affected the antioxidant activity of tomato fruit (24-63\%). Shiow and Hsin-Shan (2003) has shown that the addition of compost to 
the soil (in a 1:1 ratio) or cultivation on compost alone significantly increases the concentration of ascorbic acid and glutathione and increases the total antioxidant capacity in the fruit of two strawberry cultivars, Allstar and Honeoye. Research by Bímová and Pokluda (2009) confirmed that alternative organic fertilizers may contribute to increasing the content of antioxidants in heads of cabbage. Soil fertilization with selenium also has significant benefits. This element is known for its antioxidant properties. When transported from the soil to plants and then ingested with food by humans, it not only enriches the human diet with this element, but also delays the effects of ageing and reduces the risk of a number of diseases (Combs 2001, Hartikainen 2005, Ratajczak and Gietka-Czernel 2016). Selenium can be found in plants in the inorganic form of selenides and selenates or in an organic form as selenomethionine, but when introduced into the next link of the food chain, i.e. animals, it occurs only in the organic form (Ratajczak and Gietka-Czernel 2016). Excessive selenium content in the soil has a toxic effect on plants and other elements of the food chain (Umińska 1990).

\section{Antioxidants in the soil and the incidence of various diseases}

Antioxidants present in the soil, which are transferred to foods derived from the soil, can have a positive effect on the course of diseases associated with oxidative stress (Martinez 1995). Antioxidants present in the soil, and later transferred to food grown in the soil, can have a positive effect on the course of diseases associated with oxidative stress. Oxidative stress plays a central role in the development of chronic and degenerative diseases such as cancer, autoimmune diseases, aging, cataracts, rheumatoid arthritis, cardiovascular and neurodegenerative diseases (Pham-Huy et al. 2008). It also contributes to the formation of tumours, osteoporosis, Alzheimer's and Parkinson's disease (Martinez 1995). In humans, several mechanisms have been found to counteract oxidative stress by producing antioxidants that are either naturally produced in situ or also supplied externally by food and / or supplements (Pham-Huy et al. 2008).

\section{CONCLUSION}

Raw plant materials and plant products consumed by humans can cause many diseases, but they can also prevent and even treat them. For these reasons, it is very important to monitor soil parameters, including their physicochemical, biological and antioxidant properties. If the soil has favourable physicochemical and biological properties, it may be assumed that it should also have a high content of antioxidants. These substances are taken up from the soil together with agricultural and horticultural raw materials, and, as a consequence, they are consumed in 
plant-derived products, and will have a positive effect on our health. Regular and widespread measurement of soil antioxidant capacity would make it possible to counteract many diseases associated with oxidative stress.

Conflict of interest: The Author does not declare conflict of interest.

\section{REFERENCES}

Aminifard M.H., Aroiee H., Azizi M., Nemati H., Jaafar H.Z.E., 2013. Effect of compost on antioxidant components and fruit quality of sweet pepper (Capsicum annuиm L.). Journal of Central European Agriculture, 14(2), 525-534, https://doi.org/10.5513/JCEA01/14.2.1232

Apak R., Güçlü K., Özyürek M., Karademir S.E., Altun M., 2005. Total antioxidant capacity assay of human serum using copper (II) - neocuproine as chromogenic oxidant: the CUPRAC method. Free Radical Res., 39, 949-961, https://doi.org/10.1080/10715760500210145

Apak R., Güçlü K., Özyürek M., Çelik S.E., 2008. Mechanism of antioxidant capacity assays and the CUPRAC (cupric ion reducing antioxidant capacity) assay. Microchim. Acta, 160, 413-419, https://doi.org/10.1007/s00604-007-0777-0

Baltrusaiyte V., Venskutonis P.R., Ceksteryte V., 2007. Radical scavenging activity of floral origin honey and beebread phenolics extracts. Food Chem., 101, 502-514, https://doi.org/10.1016/j. foodchem.2006.02.007

Baran S., 2000. Assessment of the state of degradation and soil remediation (in Polish). Wyd. AR, Lublin.

Baran S., Martyn W., Krzepiłko A., Skwaryło B., Świeciło A., Onuch-Amborska J., 1999. Adaptation of the method developed by Catherine Rice-Evans and Nicholas Miller to determine the antioxidant activity of the water solution of vermicompost. Fol. Univ. Stetin., 200, Agriculturae, 77, 11-14 (in Polish).

Barto H., Fołta M., Zachwieja Z., 2005. Application of FRAP, ABTS and DPPH methods in the study of antioxidant activity of food products (in Polish). Now. Lek., 74, 4, 510-513.

Bartosz G., 2003. The second face of oxygen (in Polish). Wyd. Nauk. PWN, Warszawa.

Bednarek R., Dziadowiec H., Pokojska U., Prusinkiewicz Z., 2005. Ecological and soil research (in Polish). Wyd. Nauk. PWN, Warszawa.

Benzie I.F.F., Strain J.J., 1996. The ferric reducing ability of plasma (FRAP) as a measure of Antioxidant Power: The FRAP Assay. Anal. Biochem., 239, 70-76, https://doi.org/10.1006/ abio.1996.0292

Benzie I.F.F., Strain J.J., 1999. Ferric reducing/antioxidant power assay - direct measure of total antioxidant activity of biological fluids and modified version for simultaneous measurement of total antioxidant power and ascorbic acid concentration. Method. Enzymol., 299, 15-2, https:// doi.org/10.1016/S0076-6879(99)99005-5

Bímová P., Pokluda R., 2009. Impact of organic fertilizers on total antioxidant capacity in head cabbage. Hort. Sci. (Prague), 36(1), 21-25, https://doi.org/10.17221/9/2008-HORTSCI

Bombolewska K., Dróżdż J., Koim-Puchowsk;a B., 2013. The influence of the environment on the human antioxidant barrier. J. Ecol. Health, 17(4), 175-178.

Combs G.F., 2001. Selenium in global food systems. Br. J. Nutr., 85(5), 517-547, https://doi.org/ $10.1079 / \mathrm{BJN} 2000280$

Cybul M., Nowak R., 2008. Review of methods used in the analysis of antioxidative properties of plant extracts (in Polish). Herba Pol., 54(1), 69-78. 
Dobrzański G., Dobrzańska B.M., Kiełczowski D., 1997. Protection of the natural environment (in Polish). Wyd. Ekonomia i Środowisko, Białystok.

Evans C., Miller N.J., 1994. Methods Enzymology. Academic Press. Inc., 234, 279-293.

Frątczak J., 1996. Project of the theory of human education by the natural environment (in Polish). Zeszyty Naukowe Wyższej Szkoły Pedagogicznej w Bydgoszczy. Studia Pedagogiczne, 24, 51-68.

Georgé S., Brat P., Alter P., Amiot M.J., 2005. Rapid determination of polyphenols and vitamin C in plant-derived products. J. Agr. Food Chem., 53, 1370-1373, https://doi.org/10.1021/jf048396b

Górski M., 2006. Legal protection of lands and waters. In: Reclamation and revitalization of degraded areas (Eds S. Zawada) (in Polish). Wyd. PZITS Poznań, 11-35.

Halliwell B., Gutteridge J.M.C., 1995. The definition and measurement of antioxidants in biological systems. Free Radic. Biol. Med., 18(1), 25-26, https://doi.org/10.1016/0891-5849(95)91457-3

Hammel K.E., Kapich A.N., Jensen J.R.K.A., Ryan Z.C., 2002. Reactive oxygen species as agents of wood decay by fungi. Enzyme Microb. Technol., 30, 445-453, https://doi.org/10.1016/ S0141-0229(02)00011-X

Hartikainen H., 2005. Biogeochemistry of selenium and its impact on food chain quality and human health. J. Trace Elem. Med. Biol., 18(4), 309-318, https://doi.org/10.1016/j.jtemb.2005.02.009

Jarosz Z., 2006. Influence of the type of potassium fertilization on the chemical composition of leaves and fruits of tomato grown in various substrates (in Polish). Acta Sci. Pol. - Hortoru., 5(1), 11-18.

Jodko-Piórecka K., Litwinienko G., 2010. Oxidative stress in neurodegenerative diseases - potential antioxidative properties of catecholamines (in Polish). Post. Bioch., 56(3), 248-259.

Karbarz M., 2010. Sources of formation and environmental impact of free radicals (in Polish). Zeszyty Naukowe SGSP, 40, 59-67.

Karpińska A., Gromadzka G., 2013 Oxidative stress and natural antioxidant mechanisms - importance in the process of neurodegeneration. From molecular mechanisms to therapeutic strategies (in Polish). Postepy Hig. Med. Dosw., 67, 43-53, https://doi.org/10.5604/17322693.1029530

Kopeć K., 2008. Man in the environment and related risks. In: Threats in the modern world as a subject of geographic education (Eds J. Michalski) (in Polish). Wyd. Bernardinum, Pelplin, 60-72.

Korzeniowski P., 2012. Ecological safety as a legal institution for environmental protection (in Polish). Wyd. Uniwersytetu Łódzkiego.

Kośla T., 1999. Biological and chemical pollution of agricultural products (in Polish). Wyd. SGGW, Warszawa.

Krzepiłko A., 2005. Reactive oxygen species, antioxidants and human diseases (in Polish). Zamojskie Studia i Materiały VII, 2, 35-45.

Krzeszowiak J., 2013. Oxidative stress and the high-mountain environment (in Polish). Med. Środow. 16(1), 90-97.

Łata B., Wińska-Krysiak M., 2006. The chemical composition of kale grown on two types of soil. Acta Agroph. 7(3), 663-670.

Martinez-Cayuela M., 1995. Oxygen Free Radicals and Human Disease. Biochimie., 77, 147-161, https://doi.org/10.1016/0300-9084(96)88119-3

Mrozowska J., 1999. Laboratory of general and environmental microbiology (in Polish). Wyd. Politechniki Śląskiej, Gliwice.

Myśków W., Stachyra A., Zięba S., Masiak D., 1996. Soil biological activity as an indicator of its fertility and fertility (in Polish). Rocz. Gleb., 47(1/2), 89-99.

Pękal A.J., 2014. Effect of selection of analytic procedure on the designation of properties of antioxidant food samples (in Polish). Rozprawa doktorska, Wyd. Uniwersytet Warszawski, Warszawa.

Pham-Huy L.A., He H., Pham-Huy C., 2008. Free radicals, antioxidants in disease and health. Int. J. Biomed Sci., 4(2), 89-96. 
Prior R.L., Wu X., Schaich K., 2005. Standardized methods for the determination of antioxidant capacity and phenolics in foods and dietary supplements. J. Agr. Food Chem., 53, 4290-4302, https://doi.org/10.1021/jf0502698

Ratajczak M., Gietka-Czernel M., 2016. The influence of selenium to human health (in Polish). Post. N. Med., XXIX (12), 929-933.

Re R., Pellegrini N., Proteggente A., Pannala A., Yang M., Rice Evans C., 1999. Antioxidant activity applying an improved ABTS radical cation decolorization assay. Free Radical Biol. Med., 26, 1231-1237, https://doi.org/10.1016/S0891-5849(98)00315-3

Rimmer D.L., 2006a. Free radicals, antioxidants, and soil organic matter recalcitrance. Eur. J. Soil Sci., 57, 91-94, https://doi.org/10.1111/j.1365-2389.2005.00735.x

Rimmer D.L., 2006b. Measuring antioxidants in soil organic matter. In: Proceedings of 13th Meeting of the International Humic Substances Society, 613-616.

Rosada J., Przewocka M., 2017. Remediation and reclamation of agricultural land covered by the impact of the steel industry (in Polish). Zeszyty Naukowe Uniwersytetu Zielonogórskiego Inżynieria Środowiska, 48, 69-82, https://doi.org/10.5604/01.3001.0011.5890

Sander J., 2008. Selected aspects of environmental processes of holistic nature education in the light of the idea of sustainable development (in Polish). Problemy Ekorozwoju - Problems of Sustainable Development, 3(2), 69-80.

Schepetkin I., Khlebnikova A., Kwon B.S., 2002. Medical drugs from humus matter: Focus on mumie. Drug Develop. Res., 57(3), 40-159, https://doi.org/10.1002/ddr.10058

Sharma R.K., Agrawal M., 2005. Biological effect of heavy metals: an overview. J. Environ. Biol., 26(2), 301-313.

Shiow Y. Wang, Hsin-Shan L., 2003. Compost as a soil supplement increases the level of antioxidant compounds and oxygen radical absorbance, capacity in strawberries, J. Agric. Food Chem., 6844-6850, https://doi.org/10.1021/jf030196x

Sies H., 1995. Oxidative stress: Damage to intact cells and organs. philos. Trans. Soc. Lond. Biol. Sci., 17(311), 617-31.

Skwaryło-Bednarz B., Krzepiłko A., 2007. Biological and antioxidant properties of soils from the protected zone of Roztocze National Park. Pol. J. Environ. Stud., 16(3A), 251-254.

Skwaryło-Bednarz B., Krzepiłko A., 2008. Differentiated NPK fertilization in broad-leaved amaranth cultivation (Amaranthus cruentus L.) and total antioxidant capacity of leaves and soil under this plant (in Polish). Acta Agroph., 12(1), 173-181.

Sroka Z., Gamian A., Cisowski W., 2005. Low molecular weight antioxidants of natural origin (in Polish). Postępy Hig. Med. Dośw., 59, 34-41.

Stepnowski P., Synak E., Szafranek B., Kaczyński Z., 2010. Monitoring and analytics of pollutants in the environment (in Polish). Wyd. Uniwersytetu Gdańskiego, Gdańsk.

Szajdek A., Borowska J., 2004. Antioxidant properties of food of plant origin. Żywn.-Nauk (in Polish). Technol. Jakość, 4(41), 5-28.

Umińska R., 1990. Selenium in human environment. Rocz. Panstw. Zakł. Hig., 41(1-2), 25-34.

Verma S., Sharma A., Kumar R., Kaur C., Arora A., Shah R., Nain L., 2015. Improvement of antioxidant and defense properties of Tomato (var. Pusa Rohini) by application of bioaugmented compost. Saudi J. Biol. Sci., 22(3), 256-264, https://doi.org/10.1016/j.sjbs.2014.11.003

Wiktorowska-Owczarek A., Nowak J., 2010. Pathogenesis and prophylaxis of AMD: the role of oxidative stress and antioxidants (in Polish). Postępy Hig. Med. Dośw., 64, 333-343.

Wilczyńska A., 2009. Methods for determining the antioxidative activity of bee honeys (in Polish). Bromat. Chem. Toksykol., 42(3), 870-874. 
Wolański N., 1990. Health from an environmental perspective. In: Human-environment-health (Eds J. Kopczyński, A. Siciński) (in Polish). Wyd. Ossolineum, Wrocław, 110.

Xiong Z.T., Wang H., 2005. Copper toxicity and bioaccumulation in Chinese cabbage (Brassica pekinensis Rupr.) Environ. Toxicol., 20(2), 188-194, https://doi.org/10.1002/tox.20094

Yıldız L., Başkan K.S., Tütem E., Apak R., 2008. Combined HPLC-CUPRAC (cupric ion reducing antioxidant capacity) assay of parsley, celery leaves, and nettle. Talanta, 77, 304-313, https://doi. org/10.1016/j.talanta.2008.06.028 